\title{
Research on Inheritance and Education of Traditional Sports Culture of Ethnic Minorities
}

\author{
Defang Chen, Qiang Chen \\ Nanchang Institute of Science \& Technology, Nanchang 330108, China
}

\begin{abstract}
:
On the basis of examining the present situation of the inheritance and education of minority traditional sports culture, this paper discusses the significance of inheritance and education of minority traditional sports culture. At the same time, by explaining the advantages of school, family and community in the inheritance and education of minority traditional sports, put forward the main path to inheritance and education the construction of our national traditional sports culture.
\end{abstract}

Keywords: National traditional sports culture; inheritance and education; School

\section{1 . Introduction}

China is an ancient civilization with a long history of 5,000 years. Traditional sports of various nationalities formed during the long historical development not only become the traditional culture with distinct characteristics, but also in shaping the national identity, emotional expression and social development of the ethnic minorities in China. Exchanges lifestyles and other aspects play a very important role. However, from the end of the 19th century, after the introduction of western sports in China, with its unique value, western sports have gradually become the mainstream of our social sports. China's modern physical education, both content and form have been dominated by western modern sports technology projects. The traditional sports of various nationalities gradually become the "collections" which are not taken seriously and have been kept away from the people's social life, the school physical education teaching so that people can gradually take part in their traditional national sports in existing form, content and cultural connotation of traditional sports have a sense of strangeness 
and estrangement. Over the past decade, the school sports teaching has made some progress, all aspects of conditions have also improved, but long-term neglect of the traditional sports of ethnic minorities caused by its alienation, it is a serious subject placed in front of us. How to strengthen the social sports and school physical education, especially to enhance the students' attraction to the traditional sports culture of ethnic minority, play a role in cultivating the physical quality of students is that we need to think and solve.

\section{2 . The status quo of the inheritance and education of traditional sports culture of ethnic minorities}

Cultural heritage is the anthropologist said enculturation, refers to the process of a certain culture in the longitudinal handover between specific members of the community. The minority traditional sports cultural heritage can be understood as one kind of physical culture as a social cultural phenomenon of passing objects, is the basic means of human survival and maintaining national identity, the actual performance is a process of intergenerational transmission and receiving. The inheritance and education of traditional sports culture of ethnic minorities in China have made some progress through continuous efforts.

Chinese is a unified multi-ethnic country, since the founding of new China, great importance to the development of national sports have been attaches, the government has formulated a series of policies, and the Minority Traditional Sports mining, sorting, improve through various research methods, effective protection to the child; and since 1982, held every four years national minority traditional sports meeting, which has held 9 sessions; gradually standardized and has its own characteristic competition projects and performances, part of the national traditional sports has a strong regional project, began to become the Chinese nation recognized national sports, a good effect to the development of the traditional sports of ethnic minorities.

Social non-governmental organizations not only refer to the government to support the planned, purposeful activities of the structure of the group, but also include a number of like-minded groups composed of loose. Most of them are in a certain community to carry out activities, with strong cohesion and social mobilization ability, in the development of traditional national sports play a great role. In many areas, many traditional sports activities are carried out by the masses participation, and fully mobilize the enthusiasm of civil society, thus effectively promoting the government and society, and promote the interaction of the traditional sports culture.

The culture of each individual is acquired. Early education mainly rely on family or household, parents or teachers is the master, through words and deeds and imitation practice, made with regional and national characteristics of sports in ethnic heritage, acquisition between members. In our research, we know that in some ethnic minority areas, children often start from 5, 6 years old with their parents and adults to learn traditional sports culture. 
Many of the sports colleges and universities, the establishment of national traditional sports to this emerging industry, which is China's Sports Department of the industry reform, broaden the industry caliber; training is an important reform of national traditional sports talents to the door. Beijing Sport University, Capital Institute of Physical Education, Minzu University of China and a number of sports industry of colleges and universities has made the traditional ethnic sports for students of the industry included in the training program, teaching materials and construction, adding that industry required training venues and equipment etc.. At the same time, some primary and secondary schools have also established a national traditional sports training base, has opened a number of traditional sports, so that the national traditional sports have been developed and popularized.

\section{3. Construction of the effective path of heritage and education minority traditional sports culture.}

We have to take a holistic view of the traditional sports culture, and combine the school education, family education, social education and other forms of education to develop the national tradition through the trinity of school, family and society.

As a place of education, the school plays a very important role in carrying on the national traditional sports culture education to the students. The transmission of the national traditional sports culture is not only one of the important tasks of the school education, but also beneficial to the integrity and system of the students. National traditional sports culture and education enrich the campus sports and cultural activities.

Cultivate mechanism of ethnic minorities' traditional sports culture to talents. Historically, the traditional sports culture of ethnic minorities passed on from generation to generation to preserve the tradition, the transmission is preaching, by the older generation to the next generation. Up to now, the sports culture of minority nationalities in China still circulates in a relatively closed, inaccessible minority areas and ethnic groups in the inner group, few people understand and learn, resulting in some excellent traditional sports culture is facing loss situation. Therefore, the school to increase the training of traditional sports specialties of ethnic minorities, to build the appropriate personnel training system, while providing preferential policies, the introduction of rich theoretical knowledge and skills of national sports industry talent as a teacher, two-pronged efforts improving the quality of sports culture talents of minority.

Based on the traditional minority sports characteristics, carry out a variety of cultural campus activities. Campus sports culture as a special type of campus culture, beneficial to students to form good behavior habits, as well as healthy and progressive sports awareness and sports spirit. It is not only necessary but also meaningful to bring into play the unique function of the traditional sports culture of the ethnic minorities, enrich and activate the campus culture of the school and form distinctive features. Such as the Southwest University for 
Nationalities held in the annual "national unity and progress theme month" activities, vigorously carry out the national traditional sports project by teachers and students. Minzu University of China carry out the other national festivals sports events, not only enriched the campus life but also has formed a unique style. Some schools will be the minority traditional sports classroom teaching content and school technology activities closely together, by the hobby of national sports students.

Constructing disciplinary system of minority traditional sports and promoting the development of sports. As we all know, apart from the national economy, culture and other comprehensive national strength, it is under the influence of relevant state departmental policies, with a complete set of education system. How to optimize the combination of traditional Chinese sports resources, constitute a system of inheritance system, to enlarge its overall function and value, is to build the traditional sports education system of ethnic minorities to solve the main problems. At the same time, the traditional sports should be integrated into the education evaluation system and the school system. In the meantime, the minority nationalities' sports culture theory should be integrated into the education evaluation system and the school curriculum system make full use of physical education, elective courses and extracurricular sports activities to promote the traditional national sports culture.

In the history of all nationalities, the family through the descendants of the national history of ethnic origin, lifestyle, behavior habits, values, beliefs and customs and other aspects of education, so that future generations of national community awareness, strengthen national identity, heritage of national culture. In the process of modernization, with the adjustment of social structure and the intensification of population mobility, a large number of "left-behind children" emerged in the countryside, and the elderly became the responsibility of family care and education of children. Data show that in the western minority areas, left-behind children have also formed a large group, to the traditional culture of the nation's heritage has brought tremendous impact.

However, we are pleased to see that many young adults in soil in some national holiday also returned to his hometown, to carry out cultural activities, especially those related to national sports folklore and folk activities, participate in various sports activities, which shows cohesion of the Chinese nation and the traditional culture education, inheritance. Therefore, using the advantages of the development of national traditional sports family education mainly through the following ways: first, because the elderly family is the traditional cultural heritage and education stakeholders, is the main force in the organization of festivals and worship activities, presided over the traditional sports games, give full play to the role of the old man, and through the organization to carry out the folk cultural activities make the younger generation to develop habits and accept to participate in the activities of cultural heritage education. Second, encourage parents often take their children back home in the traditional festival activities associated with national sports, or directly involved in the design of the school and held a number of needs of students and parents to participate in the national sports, and the development of national traditional sports and cultural knowledge 
"as the theme of the parents, so that parents not only form a model the power, and let the parents in the exercise, the game imperceptibly passed to their children.

Social physical education refers to the physical education form of family and school physical education of the two independent outside of all members of the society of social sports education institutions set up by the government, public organizations or private sports education activities.

In social education, the community is its leading. We see that community sports activities is basic on community, in the area of natural environment and sports facilities as the material basis, with members of the community as the main body, to meet the various needs of sports for the purpose of various forms of sports activities. It can be seen that the construction of community culture is the best way to inherit the national traditional sports culture. From the research we know that the activities are through community groups or non-governmental organizations spontaneous activities in childhood acquisition, has a good cultural field and traditional habits, formed the traditional cultural heritage of ethnic sharing mode. Because of these ethnic minority traditional sports activities on the site, equipment, and time requirements are simpler, and thus more conducive to the development. Therefore, we can take the community as the carrier of minority sports culture into the community culture of the masses.

At the same time, we should also see the role played by the society in social sports. Many ethnic areas in our research in the inheritance of national culture, the elderly association, Heritage Association, Dragon Boat Association and other civil society plays an irreplaceable role. Of course, in the social transformation of today, the national traditional sports not only need cultural consciousness, and the national traditional sports related civil organizations also need to self-improvement, independent. Set the independent development road, and constantly promote and improve the social supervision mechanism, strengthen the sense of social responsibility of private members of the organization, improve social services, for the inheritance of Chinese traditional sports culture education, service enthusiasm and initiative.

With the wide spread of "quality education" and "lifelong physical education" and so on, a new round of reform of physical education curriculum has been set up in the field of education in china. It is very important to understand and deal with the relationship between school education, family education and social education. School, family and society between the three, although there is a certain division of labor, but it is closely linked, indispensable.

First of all, the education and inheritance of ethnic traditional sports into the school sports teaching, by trained personnel of the industry teaching, formulate the corresponding teaching objectives and plans to change the inheritance and education of national traditional sports culture, arbitrary random. Secondly, the school should be added to the national traditional sports funds, some additional facilities and the purchase of appropriate equipment, more care and attention to the national traditional sports school for the teaching of soil. Thirdly, the reform of student evaluation system is comprehensively promoted, and the knowledge and activities of national traditional sports culture are incorporated into the evaluation system. Finally, open and promote the relationship between the school 
and the community, to encourage students to actively participate in the community.

\section{Conclusion}

In a word, in China, establish family, school, community oriented education to develop the traditional ethnic sports culture, which is the core of the comprehensive inheritance and education path, not only can exercise the masses and the student body, enhance the physical quality, but also can guide people to inherit the fine traditions of Chinese culture, carrying forward and cultivating the national spirit. The traditional ethnic sports culture needs the school, family and society as the carrier of inheritance, innovation and development, and the school, family and social education needs of minority traditional sports to enrich and expand, they are interdependent, and promote each other.

\section{References:}

[1] Xia Q. Education Strategy Research on the Inheritance of the Traditional Sports Culture of Minority Ethnic[J]. Journal of Sports \& Science, 2010.

[2] Sun J, Chen Y, University X N. The Influence of Xinjiang Regional Culture on the Formation of Traditional Sports of Ethnic Minority[J]. Journal of Hengshui University, 2016.

[3] Zhang X H, Zhu M X. Features of ethnic traditional sport competition regions of Xinjiang minority[J]. Journal of Sports Adult Education, 2009.

[4] Zhang S P, Zang L H. Research into the Development of Sports Tourism Items with Xinjiang Ethnic Minority Features[J]. Journal of Chengdu Sport University, 2008.

[5] Lu Y. An Analysis on the Investing Environment of the Sports Tourist in the Minority National Region in Guangxi[J]. Sportence \& Technology, 2000. 